\title{
ECG Changes as a Predictive Tool of Outcomes in Antipsychotics Poisoned Patients
}

\author{
Doaa M. El-Gharbawy and Mona M. Ghonem ${ }^{1}$
}

${ }^{1}$ Department of Forensic Medicine and Clinical Toxicology, Faculty of Medicine, Tanta University, Tanta, Egypt.

\begin{abstract}
Background: Antipsychotics are a class of medications that are primarily used for treatment of psychosis especially schizophrenia. The most common cardio-toxic features of antipsychotics overdose are tachycardia, hypotension, and prolonged corrected QT interval. Aim: This study aimed at assessment of ECG changes utilization as a predictor of major outcome events in antipsychotic poisoned patients. Patients and methods: This prospective observational study was conducted at Tanta Poison Control Unit on 43 patients of both sexes with antipsychotics poisoning. For each patient, socio-demographic and toxicological data were collected, physical examination was performed, and routine investigations were measured. Electrocardiogram was done, and corrected QT was calculated. The severity of symptoms and signs of antipsychotics poisoning and related ECG changes were graded according to poisoning severity score. Results: This study revealed significant association between ECG grading and each of seizures, ICU admission, and in-hospital mortality. Significant association was also detected between corrected QT interval and ICU admission. Conclusion: It was concluded that, ECG changes could be used to predict mortality and major outcome events in antipsychotics intoxicated patients.
\end{abstract}

\begin{tabular}{l|l} 
Keywords & Antipsychotics; poisoning; electrocardiogram; corrected QT; intensive care unit; seizures; mortality;
\end{tabular} outcomes.

\section{Introduction}

A ntipsychotics are groups of medications that constitute the main treatment of schizophrenia (Lally \& MacCabe, 2015). Additionally, they are also approved as an adjuvant for treatment of bipolar disorders and major depressive illness (Leslie et al., 2009).

Antipsychotics are classified into typical (first generation) and atypical (second generation) groups. Chlorpromazine was the first antipsychotics drug introduced to the market in 1952, and then many antipsychotics had been developed. Meanwhile, clozapine was produced in 1990 as the first second generation atypical antipsychotics. More progression in schizophrenia treatment was marked in 2002 after the release of the third generation of antipsychotics (aripiprazole) which was approved by the U.S FDA (United Stated Food and Drug Administration) (Grady et al., 2003 and Li, 2016).

Typical antipsychotics exert their effect through antagonizing mesolimbic-dopamine $\mathrm{D}_{2}$ receptors, while, atypical antipsychotics block both $\mathrm{D}_{2}$ and corticolimbic serotonin 5-HT receptors. The new atypical antipsychotics have minimal incidence of extrapyramidal syndrome and treat positive and negative symptoms of schizophrenia. At the same time, these agents have some toxic effects such as prolonged corrected QT (QTc) interval, weight gain, and glucose intolerance (Denys \& de Haan, 2008 and Rasimas \& Liebelt, 2012).

According to National Poison Data System, antipsychotics were found to be one of the most frequently five substances responsible for human poisoning. $\quad$ Furthermore, sedative hypnotics/antipsychotics poisoning increased rapidly to constitute $10.7 \%$ of acute poisoned cases recorded in 2017 (Gummin et al., 2017). Acute antipsychotics overdose results in a variety of life-threatening toxic manifestations involving different systems. However, cardiovascular together with central nervous system manifestations are known to be the most serious. The most frequently reported cardio-toxic characteristics are tachycardia, hypotension, and prolonged QTc interval. Agitation and sedation that may extend to coma are pronounced in overdose. In addition, anticholinergic manifestations, seizures and neuroleptic malignant syndrome may occur (Minns \& Clark, 2012).

In absence of specific antidote, treatment of acute antipsychotics poisoning is based mainly on good

supportive measures. However, intensive care unit (ICU) admission may be required especially when cardio-respiratory instability and other major organ involvement are present or anticipated (Finn et al., 2009 and Levine \& Ruha, 2012). 
According to the current increase in antipsychotics prescription, the clinicians confront more cases of antipsychotics poisoning in clinical practice. Thus, predicting major outcomes in such poisoned patients is important to guide management priorities for better outcome (Meli et al., 2014 and Bhandari et al., 2018). The standard 12-lead electrocardiogram (ECG) is an available, inexpensive and non-invasive bedside test (Isiguzo et al., 2017). Hence, the aim of this study was to assess the ability to utilize ECG changes in patients with antipsychotics intoxication as a simple tool for prediction of inhospital mortality and major outcome events.

\section{Patients and methods}

This prospective observational study was conducted at Poison Control Unit, Emergency Hospital, Tanta University. It was approved by the Research Ethical Committee, Faculty of Medicine, Tanta University. All participants received detailed information concerning aim of research work, and informed consent was obtained from each participant or his/her relatives prior to commencement of the study. Personal and medical data of the patients were recorded. Coding system was used to maintain privacy and confidentiality of data and records.

\section{Inclusion criteria:}

All patients aged 12 years or more admitted to Tanta Poison Control Unit with history and/or manifestations of antipsychotics toxicity throughout the period from the $1^{\text {st }}$ of January, 2017 to the end of December, 2017 were included in this study.

\section{Exclusion criteria:}

Patients with any pre-existing chronic diseases such as cardiac, hepatic, renal hypertension, and diabetes, also, patients who received any unreported medical treatment before admission and patients of mixed drug ingestion were excluded.

Diagnosis of antipsychotics poisoning was based on history and/or manifestations of antipsychotics toxicity. A standard sheet was conducted to record complete clinical assessment of each patient. The following data were recorded for each patient; Socio-demographic data including age, gender, residence, marital state, date and time of admission. Past medical history including history of chronic systemic illness; diabetes, hypertension, cardiac, renal, liver or other diseases and history of psychiatric illness or receiving any psychiatric treatment were recorded. Pre-hospital care: if there was any intervention occurred before reaching the hospital. Toxicological data including name of drug (scientific name), drug form, route of intake, dose of drug taken, manner of poisoning, time passed from drug intake till hospital admission (delay time).

Complete clinical examination was performed for all patients including assessment of level of consciousness by Glasgow coma scale (GCS), vital signs, general examination and systemic examination. Laboratory investigations including liver enzymes (AST, ALT), kidney function tests (blood urea, serum creatinine), complete blood count (CBC), random blood glucose level, sodium $(\mathrm{Na})$ and potassium $(\mathrm{K})$ levels, arterial blood gas analysis (ABG) were measured for all patients at admission and before treatment.

The severity of symptoms and signs of antipsychotics poisoning was graded according to WHO International Program on Chemical SafetyPoisoning Severity Scale (IPCS-PSS) adopted from Persson et al. (1998) into:

- None grade: no symptoms or signs.

- Minor grade: mild, transient and spontaneously resolving symptoms; vomiting, pain, breathlessness, drowsiness, mild extrapyramidal symptoms, mild anticholinergic symptoms, mild transient hypo/hypertension, mild acid-base disturbances $\left(\mathrm{HCO}_{3} \sim 15-20 \mathrm{mmol} / \mathrm{L}, \mathrm{pH} \sim\right.$ 7.25-7.32 or 7.50-7.59) and hyperthermia of short duration.

- Moderate grade: pronounced or prolonged symptoms or signs; vomiting, pain, constipation, hypoxemia requiring extra oxygen, unconsciousness with appropriate response to pain, confusion, agitation, delirium, infrequent local or generalized seizures, pronounced extrapyramidal symptoms, pronounced anticholinergic symptoms, pronounced hypo/hypertension, pronounced acid-base disturbances $\left(\mathrm{HCO}_{3}{ }^{-}\right.$ $\sim 10-14 \mathrm{mmol} / \mathrm{L}, \mathrm{pH} \sim 7.15-7.24$ ), pronounced electrolytes disturbances $\left(\mathrm{K}^{+}\right.$2.5-2.9 mmol/L) and hyperthermia of longer duration.

- Severe grade: severe or life-threatening symptoms or signs; pneumonia, deep coma with inappropriate response to pain or unresponsive to pain, respiratory depression with insufficiency, extreme agitation, shock.

Electrocardiogram was recorded on admission, every 6 hours and when an abnormality was observed on cardiac monitor. ECGs were interpreted by a cardiologist, who was blinded to our study hypothesis and patients' data. The ECG was analyzed for rate, rhythm, axis, voltage, ST and $\mathrm{T}$ wave abnormalities, conduction defects, PR interval. Corrected QT interval was estimated according to Bazett's formula; QTc $=\mathrm{QT} / \mathrm{vRR}$ (normally up to 440 milliseconds). Echocardiogram was done as soon as possible after admission. ECG changes induced by antipsychotics poisoning were graded according to IPCS-PSS (Persson et al., 1998) into:

- Minor; Isolated extrasystoles, sinus tachycardia (HR > 100-140 in adults).

- Moderate; Sinus tachycardia (HR 140-180 in adults), frequent extrasystoles, atrial fibrillation/flutter, AV-block I-II, prolonged QRS and QTc-time, repolarization abnormalities, myocardial ischaemia.

- Severe; severe sinus tachycardia (HR >180 in adults), life-threatening ventricular dysrythmias, AV block III, asystole, myocardial infarction. 


\section{Outcome measures:}

Finally, outcome measures were recorded including primary outcome; in-hospital mortality, and other major outcome events including; seizures, ICU admission, need for mechanical ventilation and also total hospitalization period.

\section{Statistical analysis}

For quantitative data, the Shapiro-Wilk test for normality was performed. For normally distributed data, values were expressed as mean \pm standard deviation and Independent samples $\mathrm{T}$ test was performed for comparison between two groups. For data that were not normally distributed median and interquartile range (expressed as $25^{\text {th }}-75^{\text {th }}$ percentiles) were calculated and Mann-Whitney test (for comparison between two groups), Kruskal-Wallis test (for comparison between more than two groups), or Jonckheere-Terpstra test (a non-parametric test for comparison between categories of ordinal data) were used as appropriate. For qualitative data, Pearson's Chi square, Fisher's exact or Fisher-Freeman-Halton Exact tests were used to examine association between two variables. Significance was adopted at $p<0.05$ for interpretation of results of tests (Dawson-Saunders \& Trapp, 2001).

\section{Results}

During the study period, forty three patients have fulfilled the inclusion criteria and have accepted study participation. Their ages ranged between 15 and 42 years with mean age $24.9 \pm 6.9$ years; more than half of them were females $(65.1 \%)$ while males represented $34.9 \%$ of cases. Most of the studied patients were from urban areas (74.4\%) and were single (67.4\%). Moreover, $39.5 \%$ of patients gave past history of psychiatric illness and were receiving psychiatric treatment. Concerning the toxicological findings, this study revealed that, all studied patients were in suicidal attempts, no accidental exposure was recorded. Similarly, oral route was registered in all cases and $67.44 \%$ of cases were intoxicated with atypical antipsychotics. The median ingested dose of antipsychotics was $750 \mathrm{mg}$ and the recorded delay time ranged from 0.5 - 23.0 hours with median of 4 hours. Socio-demographic characteristics and toxicological findings of the participant patients were illustrated in table (1).

Clinical findings of the studied patients were demonstrated in table (2). It showed that cases with minor, moderate and severe antipsychotics toxicity were observed in 37.2\%, $20.9 \%$ 27.9\% respectively, while $14 \%$ were asymptomatic. At discharge time, $93 \%$ improved and 7\% died. During their hospital stay, 14\% suffered from seizures, $39.5 \%$ were admitted to ICU; out of them $11.6 \%$ required intubation and mechanical ventilation assistance; among those patients, $7 \%$ died. The median hospitalization period was 30 hours (table 2).

Electrocardiographic examination revealed normal ECG in 20.9\%, meanwhile, ECG changes were recorded in $79.1 \%$; among those patients $11.6 \%$ were presented with minor ECG changes, 48.8\% with moderate ECG changes and $18.6 \%$ presented with severe ECG changes as demonstrated in table (2). ECG changes recorded in our study included sinus tachycardia in 62.8\%, prolonged QTc was verified in $55.8 \%$, flat $\mathrm{T}$-wave was recorded in $11.6 \%$, while, inverted T-wave was found in $6.98 \%$. Figures $(1,2$ and 3) illustrated examples of reported ECG changes in the current study.

Table (3) revealed that, there was no significant statistical association could be detected between grading of ECG changes and any of sociodemographic data (age, gender, residence, marital status), past psychiatric history, type of antipsychotic drug, ingested dose of antipsychotics, need for mechanical ventilation or hospitalization period. While, severity of antipsychotics poisoning, delay time and some major outcome events including seizures, ICU admission and in-hospital mortality registered significant statistical association with grading of ECG changes.

It should be noted that, among patients suffered from seizures (13.9\%); 9.3\% patients registered severe ECG grading while $4.6 \%$ recorded moderate grade ECG changes. Chloropromazine, haloperidol and clozapine were the antipsychotic drugs induced seizures. Out of the ICU admitted patients (39.5\%); 18.6\% were graded as severe ECG changes and $20.9 \%$ were graded as moderate ECG changes. Also, patients who required intubation and mechanical ventilation assistance $(11.6 \%)$ showed moderate grade ECG changes in $4.7 \%$ patients and severe grade ECG changes in $6.9 \%$. On the other hand, all dead patients registered severe grade ECG changes as illustrated in table (3).

The studied group revealed mean QTc interval of $485 \pm 51$ milliseconds (range $410-590$ milliseconds) as described in table (2). Prolonged QTc interval was found in 55.8\%. Out of those patients; 23.2\% were graded as severe antipsychotics PSS, 9.3\% were graded as moderate, $16.4 \%$ were graded as minor, while, $6.9 \%$ recorded none grade antipsychotics PSS (table 4).

In-hospital mortality, seizures and need for mechanical ventilation were noticed in patients with prolonged QTc interval rather than in patients with normal QTc interval. Similarly, hospitalization period was much longer in patients with prolonged QTc interval rather than in patients with normal QTC interval. However, no significant statistical association was perceived between QTc interval and any of sociodemographic data, toxicological data, past psychiatric history, mortality, seizures, need for mechanical ventilation or hospitalization period. On the other hand, significant statistical associations were detected between QTc interval and both of severity of antipsychotics poisoning and need for ICU admission as shown in table (4). 
Table (1): Statistical analysis of socio-demographic and toxicological findings of the antipsychotics poisoned patients $(n=43)$

\begin{tabular}{|c|c|c|c|}
\hline Characteristic variables & & $\mathbf{N}$ & $\%$ \\
\hline \multirow{2}{*}{ Gender } & Male & 15 & 34.9 \\
\hline & Female & 28 & 65.1 \\
\hline \multirow{2}{*}{ Residence } & Urban & 32 & 74.4 \\
\hline & Rural & 11 & 25.6 \\
\hline \multirow{2}{*}{ Marital status } & Single & 29 & 67.4 \\
\hline & Married & 14 & 32.6 \\
\hline \multirow{2}{*}{ Past psychiatric history } & Yes & 17 & 39.5 \\
\hline & No & 26 & 60.5 \\
\hline \multirow{2}{*}{ Type of antipsychotic drug } & Typical & 14 & 32.56 \\
\hline & Atypical & 29 & 67.44 \\
\hline \multirow{2}{*}{ Age (years) } & Range & \multicolumn{2}{|c|}{$15.0-42.0$} \\
\hline & Mean \pm SD & \multicolumn{2}{|c|}{$24.9 \pm 6.9$} \\
\hline \multirow{2}{*}{ Ingested dose (mg) } & Range & \multicolumn{2}{|c|}{$16-3000$} \\
\hline & Median (IQR) & \multicolumn{2}{|c|}{$750(240-1200)$} \\
\hline \multirow{2}{*}{ Delay time (hours) } & Range & \multicolumn{2}{|c|}{$0.5-23.0$} \\
\hline & Median (IQR) & \multicolumn{2}{|c|}{$4.0(2.0-8.0)$} \\
\hline
\end{tabular}

n; number, mg; milligram, SD; standard deviation, IQR; inter-quartile range.

Table (2): Statistical analysis of clinical findings of the antipsychotics poisoned patients (number=43)

\begin{tabular}{|c|c|c|c|}
\hline \multicolumn{2}{|c|}{ Characteristic variables } & $\mathbf{N}$ & $\%$ \\
\hline \multirow{5}{*}{$\begin{array}{l}\text { PSS - Antipsychotics } \\
\text { grading }\end{array}$} & None & 6 & 14.0 \\
\hline & Minor & 16 & 37.2 \\
\hline & Moderate & 9 & 20.9 \\
\hline & Severe & 12 & 27.9 \\
\hline & Fatal & 0 & 0.00 \\
\hline \multirow[t]{5}{*}{ PSS - ECG grading } & None & 9 & 20.9 \\
\hline & Minor & 5 & 11.6 \\
\hline & Moderate & 21 & 48.8 \\
\hline & Severe & 8 & 18.6 \\
\hline & Fatal & 0 & 0.00 \\
\hline \multirow[t]{4}{*}{ Outcome $^{a}$} & Seizures & 6 & 14.0 \\
\hline & ICU admission & 17 & 39.5 \\
\hline & Mechanical ventilation & 5 & 11.6 \\
\hline & Mortality & 3 & 7.0 \\
\hline \multirow[t]{2}{*}{ QTc (milliseconds) } & Range & \multicolumn{2}{|c|}{$410-590$} \\
\hline & Mean \pm SD & \multicolumn{2}{|c|}{$485 \pm 51$} \\
\hline \multirow{2}{*}{$\begin{array}{l}\text { Hospitalization period } \\
\text { (hours) }\end{array}$} & Range & \multicolumn{2}{|c|}{$3.0-114.0$} \\
\hline & Median (IQR) & \multicolumn{2}{|c|}{$30.0(12.0-48.0)$} \\
\hline
\end{tabular}


Table (3): Statistical analysis of ECG grading against socio-demographic, toxicological and clinical data of antipsychotics poisoned patients (number $=43$ )

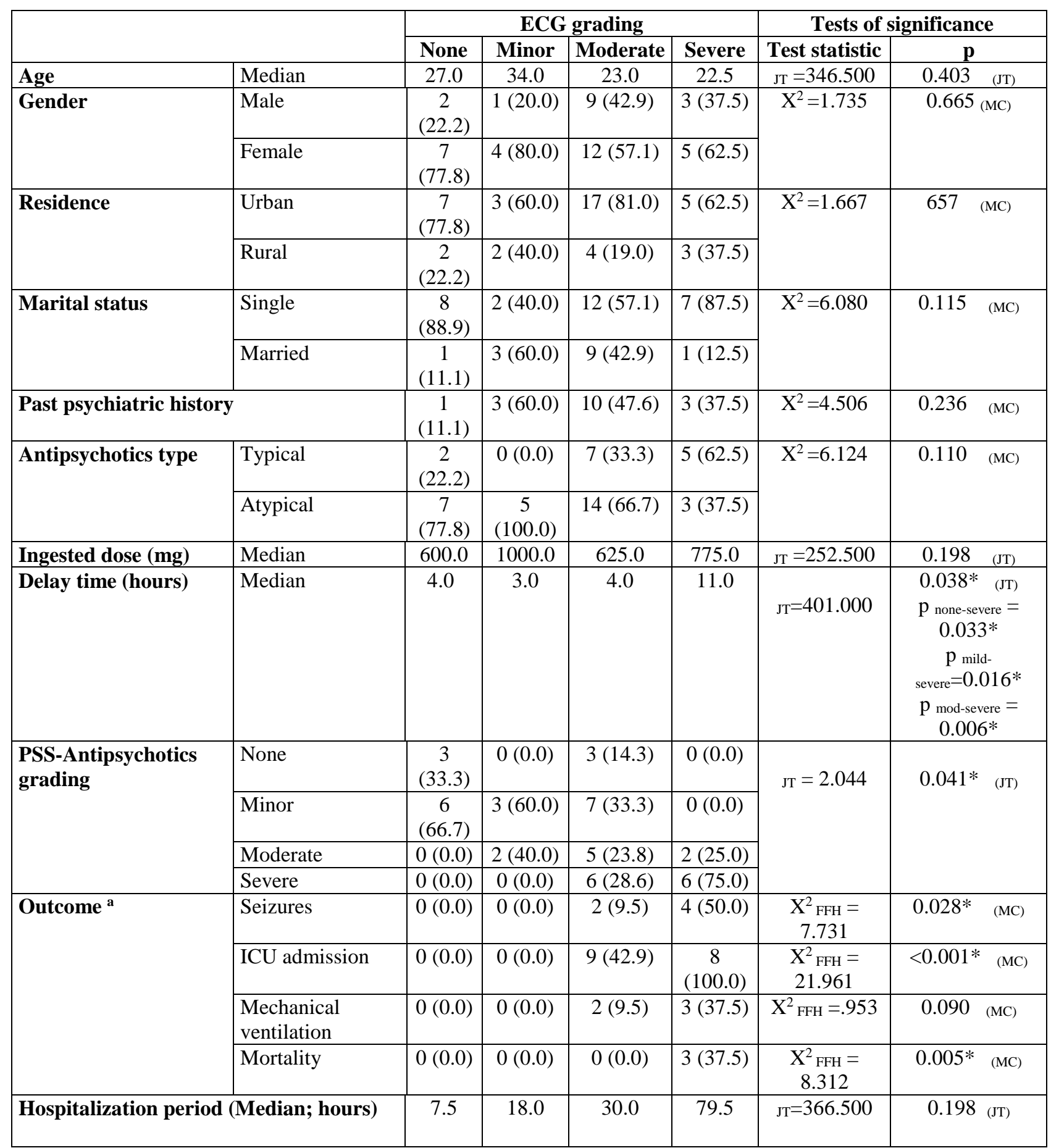

${ }^{a}$ :Outcome is not mutually exclusive, * Significant at $p<0.05 ., \mathrm{mg}$; milligram, PSS; poisoning severity score, ICU; intensive care unit, $X^{2}{ }_{F F H}$ : Fisher-Freeman-Halton exact test, $X^{2}$ : Pearson's Chi square test, MC: Monte Carlo significance, JT: Jonckheere-Terpstra test. 
Table (4): Statistical analysis of QTc against socio-demographic and toxicological data, clinical findings and outcome of antipsychotics poisoned patients (number=43)

\begin{tabular}{|c|c|c|c|c|c|}
\hline & \multicolumn{2}{|c|}{ QTc } & \multicolumn{2}{|c|}{ Tests of significance } \\
\hline & & normal & prolonged & Test statistic & $\mathbf{p}$ \\
\hline Age & Mean & 26.0 & 24.1 & $\mathrm{t}=0.859$ & 0.398 \\
\hline \multirow[t]{2}{*}{ Gender } & Male & $5(26.3)$ & $10(41.7)$ & \multirow[t]{2}{*}{$\mathrm{X}^{2}=1.100$} & \multirow[t]{2}{*}{0.294} \\
\hline & Female & $14(73.7)$ & $14(58.3)$ & & \\
\hline \multirow[t]{2}{*}{ Residence } & Urban & $13(68.4)$ & $19(79.2)$ & \multirow[t]{2}{*}{$X^{2}=0.643$} & \multirow[t]{2}{*}{0.495} \\
\hline & Rural & $6(31.6)$ & $5(20.8)$ & & \\
\hline \multirow[t]{2}{*}{ Marital status } & Single & $12(63.2)$ & $17(70.8)$ & \multirow[t]{2}{*}{$\mathrm{X}^{2}=0.285$} & \multirow[t]{2}{*}{0.745} \\
\hline & Married & $7(36.8)$ & $7(29.2)$ & & \\
\hline Past psychiatric history & Yes & $6(31.6)$ & $11(45.8)$ & $X^{2}=0.901$ & 0.369 \\
\hline \multirow[t]{2}{*}{ Antipsychotics type } & Typical & $6(31.6)$ & $8(33.3)$ & \multirow[t]{2}{*}{$X^{2}=0.015$} & \multirow[t]{2}{*}{0.903} \\
\hline & Atypical & $13(68.4)$ & $16(66.7)$ & & \\
\hline Ingested dose (mg) & Median & 750.0 & 712.5 & $\mathrm{Z}_{\mathrm{MW}}=0.416$ & 0.677 \\
\hline Delay time (hours) & Median & 4.0 & 4.5 & $\mathrm{Z}_{\mathrm{MW}}=1.476$ & 0.140 \\
\hline \multirow{4}{*}{$\begin{array}{l}\text { PSS-Antipsychotics } \\
\text { grading }\end{array}$} & None & $3(15.8)$ & $3(12.5)$ & \multirow{4}{*}{$\begin{array}{c}X_{\text {FFH }}^{2}= \\
26.781\end{array}$} & \multirow{4}{*}{$<0.001^{*}$} \\
\hline & Minor & $9(47.4)$ & $7(29.2)$ & & \\
\hline & Moderate & $5(26.3)$ & $4(16.7)$ & & \\
\hline & Severe & $2(10.5)$ & $10(41.7)$ & & \\
\hline \multirow[t]{4}{*}{ Outcome $^{\mathrm{a}}$} & Seizures & $1(5.3)$ & $5(20.8)$ & $\mathrm{FE}$ & 0.205 \\
\hline & ICU admission & $4(21.1)$ & $13(54.2)$ & $X^{2}=4.864$ & $0.027 *$ \\
\hline & $\begin{array}{l}\text { Mechanical } \\
\text { ventilation }\end{array}$ & $1(5.3)$ & 4 (16.7) & $\mathrm{FE}$ & 0.363 \\
\hline & Mortality & $1(5.3)$ & $2(8.3)$ & FE & 1.000 \\
\hline \multicolumn{2}{|l|}{$\begin{array}{l}\text { Hospitalization period } \\
\text { (Median; hours) }\end{array}$} & 19.0 & 34.5 & $\mathrm{Z}_{\mathrm{MW}}=1.824$ & 0.068 \\
\hline
\end{tabular}

${ }^{a}$ :Outcome is not mutually exclusive. * Significant at $p<0.05, \mathrm{mg}$; milligram, PSS; poisoning severity score, ICU; intensive care unit, $X^{2}{ }_{F F H}$ : Fisher-Freeman-Halton exact test, $X^{2}$ : Pearson's Chi square test, FE: Fisher's exact test, $t$ : Independent samples T test, $Z_{M W}$ : Mann-Whitney test.

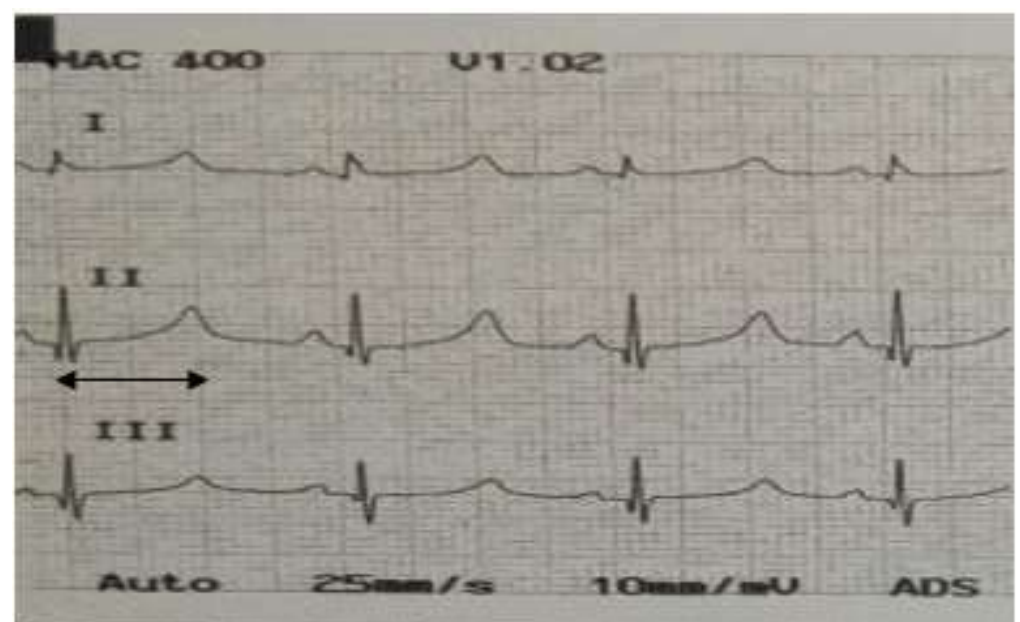

Fig. (1): An ECG of a male patient (26 years) attempted acute suicidal ingestion of olanzapine overdose presented 12 hours after ingestion showing prolonged QTe (535 msec.; $\leftrightarrow$ ) (rate: 74 beat/min, regular). 


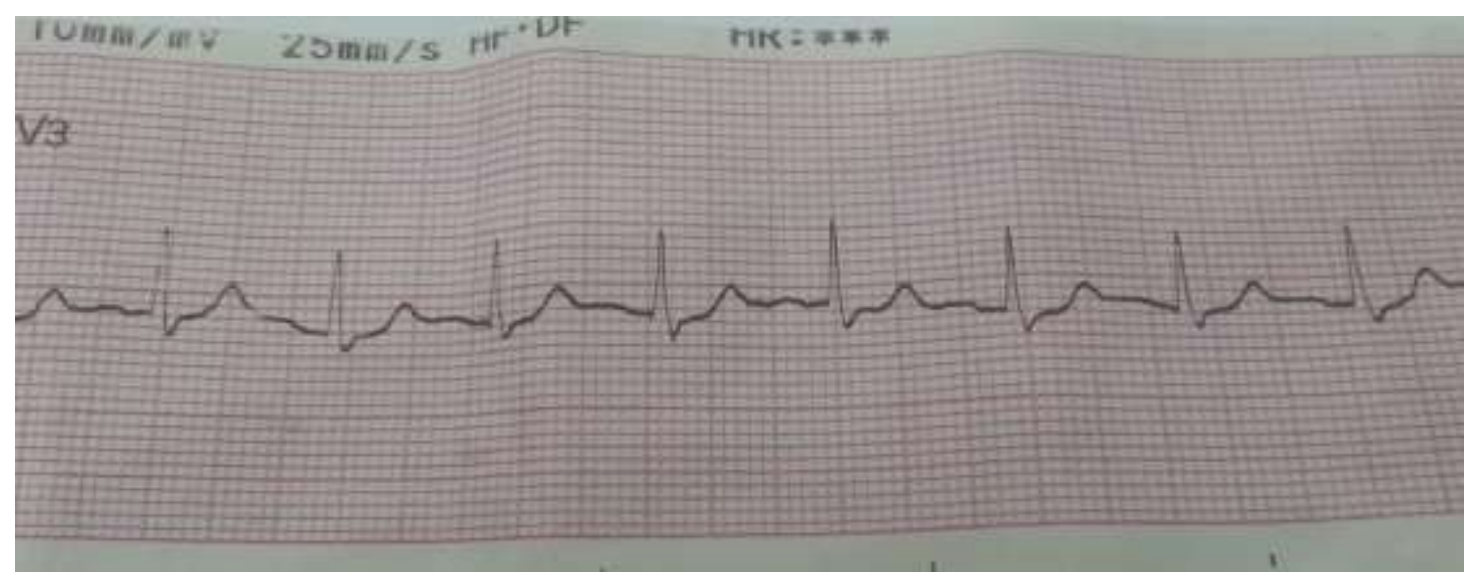

Fig. (2): An ECG of a male patient (19 years) attempted suicidal ingestion of risperidone overdose presented 4 hours after ingestion showing sinus tachycardia (rate: 122 beat/min, regular).

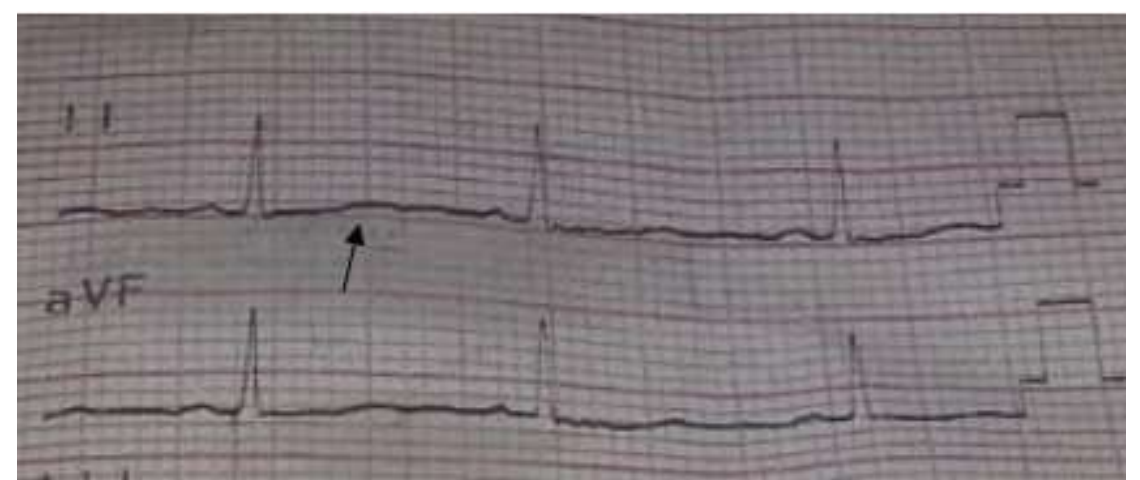

Fig. (3): An ECG of a male patient (40 years) attempted suicidal ingestion of clozapine overdose presented 8 hours after ingestion with flat $T$ wave in lead II $(\rightarrow)$ (rate: 100 beat $/ \mathrm{min}$, regular).

\section{Discussion}

Typical antipsychotics have been used for more than a half century in the treatment of different psychotic disorders. However, because of their extrapyramidal manifestations and well-established cardiovascular toxicity, atypical antipsychotics were developed in 1990s. Unfortunately, there is increasing number of reports demonstrating atypical antipsychotics associated potential toxic cardiac effects (Pal \& Valeria, 2004).

In clinical toxicology practice, ECG findings may reflect myocardial status, ion channels condition, and adrenergic tone alternation (Christopher \& Alex, 2012). The current study was designed to assess the ability to utilize ECG changes in patients with antipsychotics intoxication as a simple tool for prediction of in-hospital mortality and other major outcome events.

Socio-demographic data of the current study revealed that, the mean age of the participants was 24.9 years, all cases alleged suicidal ingestion of antipsychotic drugs. Many studies reported the predominance of intentional poisoning in young adults (Batra et al., 2003 and Ngo et al., 2008) and attributed that to the increased stressful factors nowadays specially in young adults like facing relationship, family, job and/or social problems (Singh \& Unnikrishnan, 2006 and Bronstein et al., 2009). Additionally, Finn et al. (2009) demonstrated that antipsychotics are often ingested in suicidal attempts.
This study demonstrated that the majority of cases were females (65.1\%). This was in accordance with other studies (Georgiev et al., 2015; Borg et al., 2016 and Toft et al., 2017). The explanation of this result was the concept that females use self-poisoning as a mean of deliberate self-harm rather than males who adopt highly violent methods for suicidal attempt (Boukatta et al., 2014 and Shojaei et al., 2014). Other explanations could be cultural reasons such as decreased self estimation due to low rate of employment in females, personal freedom repression whether by parents or oppressive husband, also, marriage at a young age with deprivation from having a career (Bilgin et al., 2007).

Regarding residence, it was demonstrated that most of our cases were from urban areas (74.4\%). Similar results were demonstrated by Anthony \& Kulkarni (2012) who reported that poisoning in urban areas were significantly higher than rural areas. This finding was also confirmed by Qin (2005) who reported that, people living in more urbanized areas are at a higher risk of suicide than people live in less urbanized areas. Moreover, Hammad and his colleagues (2016) explained this by the availability of pharmaceutical agents in urban areas where they are used in suicide more than pesticides which are usually used in rural area. In addition, Al-Mohamadi et al. (2013) reported that in our culture, $89.5 \%$ of 
pharmacies sell antipsychotics simply without even asking about doctor's prescription.

In the present study, $67.4 \%$ of the participants were single. This was in accordance with data obtained by Robustelli et al. (2015) who reported that, the incidence of suicidal poisoning is more frequent in single individuals.

In the current study, atypical antipsychotics were more frequently encountered than typical antipsychotics which coincided with the results of Berling et al. (2016). This could be explained by the fact that, atypical antipsychotics are widely prescribed by physicians making them a common cause of acute poisoning (Slim et al., 2016). Median of delay time was 4 hours. Generally, time between toxin exposure and seeking medical advice depends on the nature of poisoning, awareness of the family by toxicity, availability of transportation and distance of hospitals from the place of poisoning occurrence (Peranantham et al., 2014).

Regarding antipsychotics PSS grading, the current study showed $37.2 \%$ of cases were graded as minor followed by $27.9 \%$ were severe, then $20.9 \%$ of cases represented moderate grade, finally, cases who represented none grade (14\%) were the least and no fatalities were recorded. Additionally, ECG changes were recorded in $79.1 \%$ of our studied patients. These results disagreed with the results of Hammad et al. (2016) who reported that most of cases in their study were graded as either moderate, none or minor PSS grading respectively, while cases that were graded as severe or fatal represented only $1.7 \%$ for each one. Similarly, they reported lower incidence (33.4\%) of ECG changes, which could be attributed to the fact that the selected cases in their study seemed to be mild to moderate overdose. Unlike our study which revealed a higher incidence of moderate and severe cases. Meanwhile, different literatures demonstrated occurrence of ECG changes in both typical and atypical antipsychotics overdose (Tan et al., 2009 and Meli et al., 2014).

The most common ECG changes reported in the present study included sinus tachycardia and prolonged QTc. These results were similar to the findings observed by Minns \& Clark, (2012) and Borg et al. (2016). Sinus tachycardia is mediated by muscarinic $\left(\mathrm{M}_{1}\right)$, antihistaminic $\left(\mathrm{H}_{1}\right)$ and $\alpha_{1}$ adrenoceptor antagonism properties of antipsychotics (Rasimas \& Liebelt, 2012 and Nincevic et al., 2017). However, prolonged QTc is caused by K channel antagonism (Tan et al., 2009). Our recorded findings of t-wave flattening and inversion in some studied cases was in agreement with Marano et al. (2011) who stated that antipsychotics at high plasma level can result in t-wave flattening or inversion.

Concerning major outcome measures reported in the current study including seizures, ICU admission, need for ventilation assistance, and in-hospital mortality were also registered in previous studies (Magdalan et al., 2004; Ngo et al., 2008; Hammad et al., 2016 and Arici et al., 2017). The present study revealed that $14 \%$ of cases suffered from seizures, $39.5 \%$ were admitted to ICU, $11.6 \%$ needed ventilation assistance and $7 \%$ died. This partly coincided with the results reported by Berling et al. (2016) who recorded in their study that ICU admission was the highest major outcome event (15.7\%), followed by need for mechanical ventilation (10.4\%), while in-hospital mortality was detected in $0.13 \%$ of cases with antipsychotics poisoning. On the other hand, they reported that the median duration of hospital stay in their study was 18.6 hours which was shorter than that reported in our study (30 hours).

In the current study, no significant statistical association between ECG grading including QTc interval and any of socio-demographic data was observed. Metabolism of antipsychotics is mediated by cytochrome P450 isoenzymes (McNally et al., 2007). Hence, metabolic products and subsequent clinical effects including ECG changes in cases of antipsychotics poisoning may be influenced mainly by genetic variability and drug interaction rather than socio-demographic characteristics.

Interestingly, neither ECG grading nor QTc interval were significantly associated with the type of the antipsychotics or the ingested dose. Observations from previous studies revealed that, atypical antipsychotics exposure was not safer than typical antipsychotics (Ciranni et al., 2009 and Arici et al., 2017). Additionally, antipsychotics can affect ionic cardiac channels with prolongation of the action potential. In animal studies, this action was found to be dose-dependent. However, this does not always translate clinically into ECG changes in pharmacoepidemiological studies (Titier et al., 2005).

On the other hand, significant statistical association was observed between ECG grading and delay time. According to Buckley et al. (2003), findings of ECG are influenced by the time passed from ingestion. For example, ECG performed shortly after antipsychotics ingestion is much more likely to be normal in comparison with ECG done several hours after ingestion. This finding highlights the importance of repeated ECG in antipsychotics poisoning.

Herein, there was significant statistical association between antipsychotics PSS grading, seizures and ECG grading. This result was in match with Hammad et al. (2016) who found significant statistical correlation between poisoning severity grading and convulsion in acute antipsychotics poisoning. This finding can be explained by the ability of antipsychotics to lower seizure threshold (Levine \& Ruha, 2012). The previous data could explain the recorded significant statistical association between ECG grading and ICU admission in the present study.

Mechanical ventilation is required mainly for cases with respiratory complications rather than cases with cardiovascular adverse effects. This could explain lack of significant association between each of ECG grading, QTc interval and need for mechanical ventilation in the current study. Similarly, ECG grading was not significantly associated with the duration of hospital stay despite the duration of hospital stay was longer in cases with severe and moderate ECG changes in comparison with those of none and minor ECG changes. Subsequently, QTc interval did not show 
significant statistical association with mechanical ventilation or hospital stay. Larger population sample may be required to investigate these data.

In addition, the current study showed significant association between ECG grading and inhospital mortality. Reference-wise, cardiac toxicity of all antipsychotics has been demonstrated in many previous studies. Antipsychotics exert their cardiotoxic effects through blocking of ventricular myocytes ion channels modulating the cardiac action potential. Both fast $\mathrm{Na}$ inward current and slow $\mathrm{Ca}$ inward current are involved in cases of antipsychotics poisoning. However, blocking of the outward $\mathrm{K}$ currents is the most serious as it results in prolonged QT interval and life-threatening cardiac arrhythmias with subsequent increased risk of sudden cardiac death (Hennessy et al., 2002; Straus et al., 2004; Khalaf et al., 2011 and Nielsen et al., 2011).

According to our observations, seizures were more frequently recorded in patients with prolonged QTc interval however no statistical significant association could be detected between QTc interval and seizures. This finding could be supported by Kandler et al. (2005) who reported post-convulsive QT prolongation in epileptic patients but values were within normal and were reversible, they concluded that it was unclear whether QT interval could be predictive for repeated convulsions.

Despite, prolonged QT interval is widely used to predict the serious condition; torsade de pointes, but, it was found to be somewhat imprecise. Measurement of QT interval may be subjected to some errors particularly with associated T-wave changes (e.g. Twave flattening). Furthermore, the QT interval depends on the heart rate (Nielsen et al., 2011). Accordingly, QTc interval is often used instead of QT interval to predict torsade de pointes especially when QTc interval is more than 500 milliseconds (Gardner et al., 2005). Fortunately, no cases of torsade de pointes were recorded in this study. In the light of the previous data, it could be explained why prolonged QTc interval was significantly associated with antipsychotics PSS grading and ICU admission, but was not associated with mortality in the present study.

\section{Conclusions}

In the light of the previous data, it is concluded that, ECG has an important role in predicting in-hospital mortality and some major outcome events such as seizures and ICU admission in antipsychotics poisoned patients. Moreover, ECG grading is superior over QTc interval alone in predicting such outcome measures.

\section{Limitations of the study}

Small sample size and uni-center nature of the current study comprise the major limitations. Diagnosis of cases with antipsychotics poisoning was based on history and/or clinical manifestations rather than detection of the serum level which constitutes another limitation of the present study.

\section{Recommendations}

Multicenter larger prospective studies are suggested to confirm our recommendations that routine ECG monitoring in antipsychotics poisoned patients is highly essential for better management and outcome.
Also, ICU admission is considered for patients who have severe ECG changes and/or those with prolonged QTc interval.

\section{References}

Al-Mohamadi A, Badr A, Mahfouz LB et al. (2013): Dispensing medications without prescription at Saudi community pharmacy: Extent and perception. Saudi pharmaceutical journal. 21(1):13-18.

Anthony L and Kulkarni C (2012): Patterns of poisoning and drug overdosage and their outcome among in-patients admitted to the emergency medicine department of a tertiary care hospital. Indian journal of critical care medicine.16(3):130-135.

Arici MA, Şahin A, Oray NC et al. (2017): Antipsychotic exposures in an emergency department. J Basic Clin Health Sci. 2:41-46.

Batra AK, Keoliya AN, Jadhav GU (2003): Poisoning: an unnatural cause of morbidity and mortality in rural India. $\mathrm{J}$ Assoc Physicians India. 51:955-959.

Berling I, Buckley NA, Isbister GK (2016): The antipsychotic story: changes in prescriptions and overdose without better safety. British journal of clinical pharmacology. 82(1):249254.

Bhandari R, Bhandari R, Gupta PP (2018): Trend and outcome of acute poisoning case: an experience from emergency department of eastern Nepal. International Journal of Community Medicine and Public Health. 5(1):66-71.

Bilgin M, Cenkseven F, Satar S (2007): An analysis of parent-female adolescent relationships in female adolescent suicides. Crisis.28:190-197.

Borg L, Julkunen A, Madsen KR et al. (2016): Antidepressant or antipsychotic overdose in the intensive care unit - identification of patients at risk. Basic \& clinical pharmacology \& toxicology. 119(1):110-114.

Boukatta B, El Bouazzaoui GR, Houari N et al. (2014): An epidemiological study of adult acute poisoning in Fez: Morocco. J Clin Toxicol. 4(6):219.

Bronstein AC, Spyker DA, Cantilena LR et al. (2009): 2008 Annual report of the American Association of Poison Control Centers' National Poison Data System (NPDS): 26th Annual Report. ClinToxicol (Phila). 47:9111084.

Buckley NA, Chevalier S, Leditschke IA et al. (2003): The limited utility of electrocardiography variables used to predict arrhythmia in psychotropic drug overdose. Critical Care. 7(3):101-107.

Christopher Y, Alex FM (2012): Utility of the electrocardiogram in drug overdose and poisoning: Theoretical considerations and clinical implications. Current Cardiology Reviews. 8(2):137-151. 
Ciranni MA, Kearney TE, Olson KR (2009): Comparing acute toxicity of first- and secondgeneration antipsychotic drugs: a 10-year, retrospective cohort study. J Clin Psychiatry. 70:122-129.

Dawson-Saunders B and Trapp R (2001): Basic and clinical biostatics. $3^{\text {rd }}$ Edition. McGrow Hill, McGrow Hill Medical Publishing Division, P.P. 212-220

Denys D, de Haan L (2008): 25 years antipsychotics: back to the future?. Tijdschrift voor psychiatrie.50 Spec no.:105-109.

Finn SDH, Uncles DR, Willers J et al. (2009): Early treatment of a quetiapine and sertraline overdose with Intralipid.Anaesthesia. 64(2):191-194.

Gardner DM, Baldessarini RJ, Waraich P (2005): Modern antipsychotic drugs: a critical overview. CMAJ. 172(13):1703-1711.

Georgiev K, Georgieva M, Marinov P et al. (2015): Acute poisonings with neuroleptics in clinic of toxicology of military medical academy Varna/Bulgaria registered for 20 year period. Scripta scientifica medica. 47(1):70-72.

Grady MA, Gasperoni TL, Kirkpatrick P (2003):

Aripiprazole. Nature reviews drug discovery.2(6):427- 428.

Gummin DD, Mowry JB, Spyker DA et al. (2017): 2016 Annual Report of the American Association of Poison Control Centers' National Poison Data System (NPDS): 34th Annual Report. Clinical toxicology. 55(10):1072-1254.

Hammad SA, GirgisNF, Amin SA et al. (2016): Evaluation of acute antipsychotic poisoned cases. Menoufia Medical Journal. 29(4):11161121.

Hennessy S, Bilker WB, Knauss JS et al. (2002). Cardiac arrest and ventricular arrhythmia in patients taking antipsychotic drugs: Cohort study using administrative data. BMJ. 325:1070-1074.

Isiguzo GC, Iroezindu MO, Muoneme AS et al. (2017): Knowledge and utilization of electrocardiogram among resident doctors in family medicine in Nigeria. Nigerian Journal of Clinical Practice. 20(9):1133-1138.

Kandler L, Fiedler A, Scheer K et al. (2005): Early post-convulsive prolongation of QT time in children. Acta Paediatrica. 94(9):1243-1247.

Khalaf MA, Abdelrahman TM, Abbas MF (2011): Values of using QTc and N-terminal fragment of B-type natriuretic peptide as markers for early detection of acute antipsychotic drugsinduced cardiotoxicity. Cardiovasc Toxicol.11(1):10-17.

Lally J, MacCabe JH (2015): Antipsychotic medication in schizophrenia: a review. British Medical Bulletin. 114(1):169-179.

Leslie DL, Mohamed S, Rosenheck RA (2009): Offlabel use of antipsychotic medications in the department of Veterans Affairs Health Care
System. Psychiatric Services. 60(9):11751181.

Levine M, Ruha A (2012): Overdose of atypical antipsychotics: Clinical presentation, mechanisms of toxicity and management. CNS Drugs. 26(7):601-611.

Li M (2016): Antipsychotic-induced sensitization and tolerance: Behavioral characteristics, developmental impacts, and neurobiological mechanisms. J Psychopharmacol. 30(8):749770.

Magdalan J, Wasyko-Smolarek M, Antończyk A et al. (2004): Intoxications with atypical antipsychotic drugs--data of the Acute Intoxication Unit in Wrocław. PrzeglLek. 61:392-396.

Marano G, Traversi G, Romagnoli E et al. (2011): Cardiologic side effects of psychotropic drugs. Journal of Geriatric Cardiology : JGC. 8(4):243-253.

McNally P, McNicholas F, Oslizlok P (2007): The QT interval and psychotropic medications in children. European Child \& Adolescent Psychiatry. 16(1):33-47.

Meli M, Rauber-Lüthy C, Hoffmann-Walbeck P et al. (2014): Atypical antipsychotic poisoning in young children: a multicentre analysis of poisons centres data. European Journal of Pediatrics. 173(6):743-750.

Minns AB, Clark RF (2012): Toxicology and overdose of atypical antipsychotics. J Emerg Med. 43:906-913.

Ngo A, Ciranni M, Olson KR (2008): Acute quetiapine overdose in adults: a 5-year retrospective case series. Ann Emerg Med. 52:541-547.

Nielsen J, Graff C, Kanters JK et al. (2011): Assessing QT interval prolongation and its associated risks with antipsychotics. CNS Drugs. 25(6):473-490.

Nincevic Z, Lasic D, Glavina T et al. (2017): Quetiapine poisoning associated with neuroleptic malignant syndrome, rhabdomyolysis and renal failure: A case report. Psychiatria Danubina. 29(1):84-86.

Pal P, Valeria K (2004): Cardiovascular side effects of new antidepressants and antipsychotics: new drugs, old concerns?. Current Pharmaceutical Design. 10(20):2463-2475.

Peranantham S, Shaha KK, Sahai A et al. (2014): Hospital based epidemiological study of deaths due to organophosphorous compound poisoning. Indo American Journal of Pharmaceutical Research. 4(9):3773-3779.

Persson HE, Sjoberg GK, Haines JA et al. (1998): Poisoning Severity Score. Grading of acute poisoning. Clinical Toxicology. 36(3):205213.

Qin P (2005): Suicide risk in relation to level of urbanicity - a population-based linkage study. International Journal of Epidemiology. 34(4):846-852.

Rasimas JJ, Liebelt E (2012): Adverse effects and toxicity of the atypical antipsychotics: What is 
important for the pediatric emergency medicine practitioner?. Clin Pediatr Emerg Med. 13(4):300-310.

Robustelli BL, Trytko AC, Li A et al. (2015): Marital discord and suicidal outcomes in a national sample of married individuals. Suicide and Life-Threatening Behavior. 45(5):623-632.

Shojaei A, Moradi S, Alaeddini F et al. (2014): Association between suicide method, and gender, age, and education level in Iran over 2006-2010. Asia Pacific Psychiatry. 6(1):1822.

Singh B, Unnikrishnan B (2006): A profile of acute poisoning at Mangalore (South India). Journal of Clinical Forensic Medicine. 13(3):112-116.

Slim M, Medina-Caliz I, Gonzalez-Jimenez A et al. (2016): Hepatic safety of atypical antipsychotics: Current evidence and future directions. Drug Safety. 39(10):925-943.

Straus SM, Bleumink GS, Dieleman JP et al. (2004): Antipsychotic and the risk of sudden cardiac death. Arch Intern Med. 164:1293-1297.

Tan HH, Hoppe J, Heard K (2009): A systematic review of cardiovascular effects after atypical antipsychotic medication overdose. Am J Emerg Med. 27(5):607-616.

Titier K, Girodet P, Verdoux H et al. (2005): Atypical antipsychotics: From potassium channels to torsade de pointes and sudden death. Drug Safety. 28(1):35-51.

Toft S, Horwitz H, Dalhoff KP (2017): Long-term mortality after poisoning with antipsychotics. Clinical toxicology. 55(4):267-274.

\section{الملخص العربى}

\section{التغيرات فى تخطيط القلب الكهربائى كأداة تنبؤية بنتائج مرضى التسمم بمضادات الذهان دعاء محمد الغرباوى و منى محمد غنيم}

$$
\begin{aligned}
& \text { الحلفية العلمية: تعتبر مضادات الذهان مجموعة من الأدوية التي تستخدم فن المقام الأول لعلاج أمراض الذهان و خاصة مرض } \\
& \text { انفصام الشخصية. وتعد زيادة عدد دقات القلب، وانخفاض ضغط الدم، وزيادة طول الفاصلة QT المعدلة هى الخصائص السمية القلبيّة }
\end{aligned}
$$

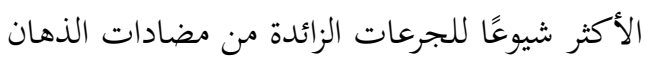

$$
\begin{aligned}
& \text { الهدف من البحث: هدفت هذه الدراسة إلى تقييم استخدام التغييرات في تخطيط القلب الكهربائى كمؤشر للتنبؤ بأهم نتائج } \\
& \text { مرضى التسمم بمضادات الذهان. } \\
& \text { المرضى وطرق البحث: وقد أجريت هذه الدراسة على بـ مريضًا من الجنسين يعانون من جرعة زائدة من مضادات الذهان }
\end{aligned}
$$

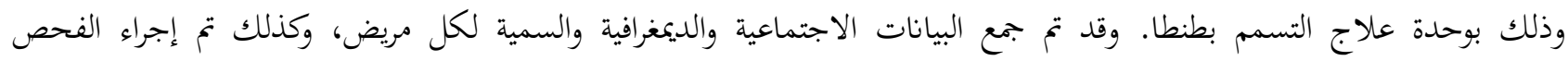

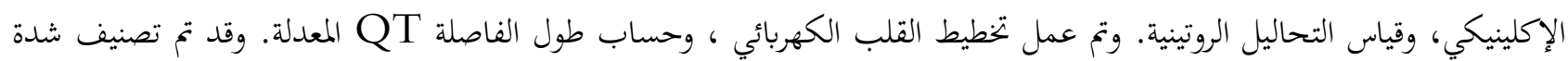

$$
\begin{aligned}
& \text { أعراض وعلامات التسمم بمضادات الذهان وكذلك التغيرات فن تخطيط القلب الكهربائى المصاحبة طبقاً لمقياس شدة التسمهم. } \\
& \text { النتائج: أظهرت هذه الدراسة ارتباطاً ذا دلالة إحصائية بين درجات التغيرات فن تخطيط القلب الكهربائي وكل من التشنجات، }
\end{aligned}
$$

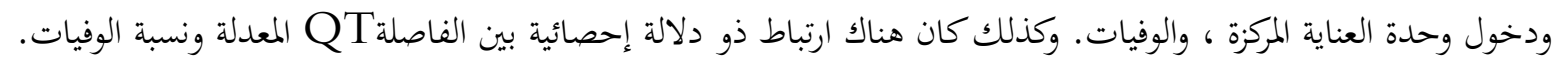

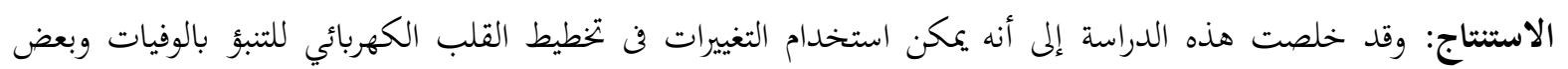

$$
\begin{aligned}
& \text { النتائج الرئيسية في المرضى الذين يعانون من التسمم بمضادات الذهان. } \\
& \text { الكلمات المفتاحية: مضادات الذهان، التسمم، تخطيط القلب الكهربائى، الفاصلة QT المعدلة،وحدة العناية المركزة، } \\
& \text { التسنجات، الوفيات، النتائج. }
\end{aligned}
$$

